\title{
A Novel Model Concerning the Independence of Emissivity and Absorptivity for Enhancing the Sustainability of Radiant Cooling Technology
}

\section{Fan Zhang}

Hunan University College of Civil Engineering

Guoqiang Zhang ( $\sim$ gqzhang@hnu.edu.cn )

Hunan University College of Civil Engineering https://orcid.org/0000-0003-3781-6874

\section{Research Article}

Keywords: Radiant heat transfer coefficient, Emissivity, Absorptivity, error, Kirchhoff's law

Posted Date: December 10th, 2021

DOI: https://doi.org/10.21203/rs.3.rs-751145/v1

License: (c) (i) This work is licensed under a Creative Commons Attribution 4.0 International License.

Read Full License 


\section{Abstract}

Radiant cooling technology is a sustainable technology for improving built environment. The past research only studied the performance (e.g., radiant heat flux) based on Kirchhoff's law while the accuracy and its reasons were seldom analyzed. In order to study the mechanism deeply, a new model of radiant heat transfer is derived theoretically which considers emissivity and absorptivity independently. This model is validated by the experimental data then applied in a reference case for further analysis. The analyzing methods of sensitivity and relative deviation are performed to investigate the reasons for the errors. The results of sensitivity analysis show that it is about $20 \%-40 \%$ more sensitive for the emissivity to the heat flux than the absorptivity. Furthermore, the deviation of the heat flux can reach up to $20 \%$ when the absorptivity is in the range from 0.4 to 0.9 . This deviation is close to the estimated error range of $21.8 \%$ in the past studies. Therefore, the discussion based on the theoretical analysis, shows that the errors in past studies are highly due to the oversimplified preconditions for applying Kirchhoff's law and they ignored the impact of surface absorption. Additionally, the validation in the previous experiments was highly coincidence, since they neglected the key independent tests of the absorptivity and radiant heat flux. Comprehensively, the new model is valuable to provide a more reliable solution for analyzing the radiant heat transfer and for the future design of an independent test of radiant heat flux.

\section{Introduction}

Radiant cooling (RC) systems have been widely applied in recent years due to their advantages of energysaving and thermal comfort (Rhee et al. 2017; Zhang et al. 2021). While it is still complicated to explain the deep reasons for better energy-saving and thermal comfort than the conventional convective cooling systems such as fan coil cooling systems or all air cooling systems during the contrastive studies (Saber et al. 2016). Radiant heat transfer analysis is the most important method for exploring the reasons for the energy saving in RC systems. As long as the analysis is performed scientifically and rigidly, the reason will be shown by comparing the differences during the analysis. The radiant heat transfer on a surface is mainly affected by four factors i.e., temperature, emissivity, absorptivity, and spectrum (Modest 2013). The emissivity and absorptivity are the vital factors, since the impacts of the other factors (i.e., the temperature and spectrum) could be relatively controlled in a radiant environment. In addition, they are also the vital different factors from that in the heat exchange process of convective cooling systems (Karadağ 2009). Therefore, it is necessary to figure out the mechanism and the impact of the emissivity and absorptivity during the thermal analysis of the radiation. Thence, it will be helpful to enhance the reliability of analytical results and of the validation during the experimental design and engineering practice for a radiant environment.

The current methods for analyzing the radiant heat transfer could be included as the methods of heat transfer coefficient, thermal resistance network, and area-weighted average uncooled surface temperature (AUST). The heat transfer coefficient method treats the radiant heat flux as that is proportional to the temperature difference between the radiant surface and the air. The proportional coefficient is recommended as $5.5 \mathrm{~W} /\left(\mathrm{m}^{2} \mathrm{~K}\right)$ according to Olesen's study (Olesen et al. 2000). The current international 
standards (e.g., EN 1264-5 and EN 15377-1) have adopted this method as a predicting method for radiant heat flux. In addition, AUST method treats the average temperature of uncooled surfaces as the reference temperature for analyzing the radiant heat flux. Then, the coefficient of radiant heat transfer can be gained by only the temperatures of indoor surfaces. Although this method neglects the impact of the radiative angle factor, it is still the main method for characterizing the radiant heat transfer. For instance, Acikgoz (Acikgoz and Kincay 2015) analyzed the coefficient can be as small as $4.16 \mathrm{~W} /\left(\mathrm{m}^{2} \mathrm{~K}\right)$ with the AUST method. Additionally, Koca (Koca et al. 2014) obtained the parameter can be up to $6.25 \mathrm{~W} /\left(\mathrm{m}^{2} \mathrm{~K}\right)$ with the same method. While these two methods are too simplified to concern the radiant surface characters in equations.

Thermal resistance network is a popular method for analyzing a heat transfer process, but it is based on the inference that the emissivity is equal to its absorptivity for a radiant surface (Lienhard IV et al. 2018; Wang et al. 2019). This inference is widely adopted in the current studies of RC systems (Su et al. 2015; Zhao et al. 2015). Nevertheless, this method has to neglect the impact of heat storage in the normal applications of thermal resistance network. Thereafter, RC-network is applied to concern the impact of the heat storage that based on the mechanism of thermal resistance network. Because this method consists of a new module modeling a thermal capacitor to concern the impact of the thermal loss at a specific point. For example, Zhang (Zhang et al. 2016) applied the RC-network in analyzing the radiant heat flux across the indoor space. And, the thermal loss process on the indoor surfaces is simplified as a capacitor. Except, this method could also be successfully applied in studying the heat transfer between the indoor and the outdoor atmosphere (Bueno et al. 2012). Although this method has been further optimized by Weber (Weber and Jóhannesson 2005), it is still based on the assumption that the emissivity equals the absorptivity and it cannot solve the problem due to the impact of heat storage in the radiant surface layers.

Indeed, these methods have their theoretical obstacles to explain the errors of radiant heat flux in real experiments or tests. According to Shinoda's review (Shinoda et al. 2019), the coefficient of radiant heat transfer ranges from $4.3-6.25 \mathrm{~W} /\left(\mathrm{m}^{2} \mathrm{~K}\right)$. Which differs from Olesen's recommended value by that between $-21.8 \%$ and $13.6 \%$. This range of the coefficient error implies that it will make the total error of radiant heat flux be around $10-20 \%$ in engineering. But, for theory, this ratio of error is a little large to explain the reasons. Moreover, the method of thermal analysis in the above studies is by thermal resistance network, which is indeed derived from Kirchhoff's law. And with Kirchhoff's law, we can obtain that the emissivity of a radiant surface is equal to its absorptivity. However, Kirchhoff's law has necessary conditions imposed on it (Howell et al. 2015). It requires the radiant surface to be in local thermal equilibrium with the radiant environment, or the surface condition can be simplified into it. This is very difficult in real RC environment. However, the instruments for testing the radiant heat flux have adopted Kirchhoff's law and apply it in calculating the radiant heat flux automatically, such as an infrared imaging camera (Cholewa et al. 2017). This definitely hinders the validation of radiant heat flux. Therefore, the current methods that based on Kirchhoff's law are making the self-validation cases by applying such 
instruments in testing. This concerns most of the past testing cases. In this study, some other preconditions are not discussed, e.g., the assumption of grey body and diffuse surface.

In addition, there is a lack of direct supports of experimental data to validate the engineering coefficients for radiant heat flux. The current data for the validation of radiant heat flux were always obtained by abstracting the analytical value of the radiant heat flux from the experimental value of the total cooling capacity (Causone et al. 2009; Cholewa et al. 2017; Shinoda et al. 2019), or vice versa for the convective heat flux. This is not the validation for the radiant heat flux, nor the convective. These data of radiant heat flux are obtained by self-verification in the thermal analysis and is lack of solid validation with an independent test of radiant heat flux. Hence, the abstracted data is still analytical results, and it is not reasonable to be the support of experimental validation.

Moreover, the absorptivity of building materials is not always equal to its emissivity for a same radiant surface. For example, Liu (Liu and Geng 2004) applied the spectrophotometer to test the absorptivity of concrete directly and found that the absorptivity could be as low as 0.4 . And then, Carnielo (Carnielo et al. 2014) tested some conventional materials that could be used in buildings with the method of Integrating sphere. The results showed that the absorptivity would range from $0.5-0.6$ for smooth light grey surfaces. Hence, the real value of absorptivity on a radiant surface may be much smaller than 0.9 . However, the absorptivity is always assumed to be equal to the emissivity of 0.9 (Koca and Çetin 2017; Zhang et al. 2018; Zhou et al. 2019), though the absorptivity of conventional materials in buildings indeed varies from $0.4-0.9$. Thence, the absorptivity is highly different from the value of 0.9 , which is usually adopted in the past studies. Further, the inference that the emissivity is equal to the absorptivity, is unavailable in reality.

Comprehensively, the current research is indeed lack of enough support to explain the mechanism for the errors in thermal radiation. All the above methods for analyzing the radiant heat flux were based on oversimplified deduces. Additionally, there was lack of solid experiment validation on real radiant heat flux and quantitative analysis on the error reasons. Seldom case could be found about independent testing on the radiant heat flux in a radiant room. Besides, the heat flux of convention was not controlled rigidly or not validated legimately at the mean time. However, the radiant heat exchange occupies more than $50 \%$ of the whole heating or cooling capacity in the room (Feng et al. 2016). It is crucial of the thermal radiation analysis for the mechanism research of energy saving and heat transfer. Besides, the emissivity and absorptivity are most relative to the result of the analysis. While they are lumped based on Kirchhoff's law in the most current studies. Therefore, Kirchhoff's law is highly overestimated to introduce the errors in the application of actual engineering projects. Thence, the research on the impact of radiant surface characters is valuable for future research on energy saving potential (in which degree) and engineering design. This article will try to explain the errors of radiant heat flux that emerged in past studies and the influence of the independent radiant factors.

In order to investigate the impact of the surface characters (i.e., the emissivity and absorptivity) on RC systems, this study reviews the mechanism of the analyzing methods for radiant heat flux that applied in 
past studies. Then, Sect. 2 illustrates the fundamental theories and methodology for studying the surface characters on radiant heat transfer. A new thermal model is put forward concerning the independence of emissivity and absorptivity. And, it is applied in a reference case for further analysis regarding the impact of surface characters. In Sect. 2.4, the new model is validated by experimental data under a typical condition. Based on the new model, Sect. 4, and gives the quantitative results of the sensitivity and deviation analysis in terms of radiant heat flux, cooling capacity, and heat transfer coefficient. Spectacularly, important results are discussed to explain the reasons for the potential errors caused by the errors of emissivity and absorptivity. In the end, Sect. 7 concludes the research method and the main results in this article.

\section{Theory And Methodology}

In this section, a new thermal model for analyzing the heat transfer of thermal radiation will be put forward. The new model is based on the nodal network method, but it further concerns the dynamic characters of the emissivity and absorptivity on the radiant surfaces. Based on the developed model, an experimental case is then put forward for validation and for analyzing the impact in a real indoor environment further. Thereafter, the method of sensitivity analysis is applied to analyze the influencing power of the factors. Besides, the relative deviation analysis is also performed to show the differences between the past theories and real errors.

\subsection{Fundamental theory for developing the thermal model}

The comparison between the premises of the current models and the new model for analyzing the thermal radiation is shown in Fig. 1. Both the models adopt the assumption of graybody and diffuse surface. With the assumption of graybody and diffuse surface, the emission and absorption could be regarded irrelevant to the direction and the spectrum of the radiation, separately. In addition, temperature is also assumed unrelated to the emissivity and absorptivity, since the impact of temperature are mainly on the emissive power (shown in Eq. (3)) other than the physical properties of the surface material in low temperature environment of RC. Thence, the emissivity and absorptivity could be simplified as the follows.

$\boldsymbol{\epsilon}=\boldsymbol{\epsilon}_{\boldsymbol{\lambda}}=\boldsymbol{\epsilon}_{\boldsymbol{\theta}}=\boldsymbol{\epsilon}_{\boldsymbol{T}}$
$\alpha=\alpha_{\lambda}=\alpha_{\theta}=\alpha_{T}$
$\alpha$

Nevertheless, the establishment of Kirchhoff's law in real engineering is indeed based on some premises which are reviewed in Sect. 1. The premises for applying Kirchhoff's law are too critical in real indoor environment, as discussed in Sect. 6.1. Thus, the application of Kirchhoff's law has to be abandoned (shown in Fig. 1 (b)) in order to describe the radiant heat exchange more accurately in real environment. Thence, the inference that the emissivity of a radiant surface is equal to its absorptivity is invalid, 
because the basis of the inference is invalid. Moreover, the radiosity emitted from a surface could be given by Stefan-Boltzmann law (Modest 2013).

$$
E_{b}=\sigma T^{4}
$$

Additionally, based on the energy conservation law, the heat flux will be equal to the difference between the effective heat flux of radiosity $J$ and the locally incident radiation heat flux $G$

$$
q=J-G
$$

Then, on any two surfaces 1 and 2, we can derive a series of formulas from the angle factor theory and Eq. (4) as follows:

$$
\begin{aligned}
& q_{1}=\epsilon_{1} E_{b, 1}-\alpha_{1} G_{1} \\
& \Phi_{1,2}=A_{1} J_{1} X_{1,2}-A_{2} J_{2} X_{2,1}
\end{aligned}
$$

Where, $X_{1,2}$ is the view factor between two surfaces could be calculated by (Modest 2013)

$$
X_{1,2}=\frac{1}{A_{1}} \int_{A_{1}} \int_{A_{2}}{ }^{\cos \theta_{1}-\cos \theta_{2}} \frac{\pi^{2}}{\Pi S^{2}} d A_{2} d A_{1}
$$

Further, the radiosity on two surfaces can be obtained by

$$
\begin{aligned}
& J_{1}=\frac{\epsilon_{1}}{\alpha_{1}} E_{b, 1}-\left(\frac{1}{\alpha_{1}}-1\right) q_{1,2} \\
& J_{2}=\frac{\epsilon_{2}}{\alpha_{2}} E_{b, 2}-\left(\frac{1}{\alpha_{2}}-1\right) q_{2,1} \\
& \Phi_{1,2}=-\Phi_{2,1}
\end{aligned}
$$

Introduce Eq. (8), (9), and (10) into (6), we can solve out the radiant heat flux between any surface 1 and 2 in Eq. (11). In the equation, the emissivity and absorptivity is independent of each other. Thence, this developed model is more universally applicable in reality.

$$
\Phi_{1,2}=\frac{\sigma_{b}\left(\frac{\epsilon_{1}}{\alpha_{1}} T_{1}^{4}-\frac{\epsilon_{2}}{\alpha_{2}} T_{2}^{4}\right)}{\frac{1-\alpha_{1}}{\alpha_{1} A_{1}}+\frac{1}{A_{1} X_{1,2}}+\frac{1-\alpha_{2}}{\alpha_{2} A_{2}}}
$$

\subsection{The developed model for analyzing the case}


In order to analyze the impact of surface characters on a radiant environment, Niu's case (Niu et al. 2014) has been chosen for applying the model derived in the last part. The detailed information about the engineering could be referenced in Niu's article. Only the key information regarding the topics will be given in the following paragraphs (also in Fig. 2 (a)) in case of wordy. Further, the 3D nodal model of the reference case is abstracted and shown in Fig. 2 (b). Based on the developed model, the heat flux from the surface of the radiant panel to the wall surface 1 can be described as

$$
\Phi_{r, p, 1}=\frac{\sigma\left(\frac{\epsilon_{1}}{\alpha_{1}} T_{1}^{4}-\frac{\epsilon_{p}}{\alpha_{p}} T_{p}^{4}\right)}{\frac{1-\alpha_{1}}{A_{1} \alpha_{1}}+\frac{1}{A_{1} X_{1, p}}+\frac{1-\alpha_{p}}{A_{p} \alpha_{p}}}
$$

Similarly, the radiant heat flux from the panel to any other surface $j$ is

$$
\Phi_{r, p, j}=\frac{\sigma\left(\frac{\epsilon_{j}}{\alpha_{j}} T_{i}^{4}-\frac{\epsilon_{p}}{\alpha_{p}}{ }^{4}{ }_{p}{ }^{4}\right)}{\frac{1-\alpha_{j}}{A_{j} \alpha_{j}}+\frac{1}{A_{j} X_{j, p}}+\frac{1-\alpha_{p}}{A_{p} \alpha_{p}}}
$$

With the previous equations, the independent characters of the emissivity and absorptivity are retained for the reference case. Further, the emissivity of the inner surfaces of the walls and radiant panels are simplified as the same, since they are often applied with identical materials. This regulation and result also applies to the absorptivity. Thereafter, the cooling capacity $\Phi_{p, i}$ could also be revised as the following equations based on Niu's case (Niu et al. 2014):

$$
\begin{aligned}
& \Phi_{\boldsymbol{p}}=\boldsymbol{\Phi}_{\boldsymbol{r}, \boldsymbol{p}, \boldsymbol{i}}+\boldsymbol{\Phi}_{\boldsymbol{r}, \boldsymbol{p}, \mathbf{1 - 5}}+\boldsymbol{\Phi}_{\boldsymbol{c}, \boldsymbol{p}, \boldsymbol{a}} \\
& \Phi_{r, p, 1-5}=\sum_{j=1}^{5} \frac{\sigma \frac{\epsilon_{j}}{\alpha_{j}}\left(T_{j}^{4}-T_{p}^{4}\right)}{\frac{1-\alpha_{j}}{A_{j} \alpha_{j}}+\frac{1}{A_{j} X_{j, p}}+\frac{1-\alpha_{p}}{\alpha_{p} A_{p}}} \\
& \Phi_{C, p, a}=h_{p, a} A_{p}\left(T_{a}-T_{p}\right)
\end{aligned}
$$

The new model for the thermal resistance of surface 1 can be described as the following equation which is easy for comparing with the thermal resistance in past studies.

$$
R_{r, p, 1}=\frac{\Phi_{r, p, 1}}{\sigma\left(T_{1}^{4}-T_{p}^{4}\right)}
$$

In addition, the coefficient of heat transfer could be given by AUST method, and the following equations illustrate the coefficient in the reference case: 


$$
h_{r}=\frac{\Phi_{r, p, 1-5}}{A U S T-T_{P}}
$$

Where AUST could be obtained by the definition in ASHRAE (ASHRAE 2016)

\subsection{Sensitivity analysis}

$$
A U S T=\sum_{j=1}^{5} A_{j} T_{j} / \sum_{j=1}^{5} A_{j}
$$

Sensitivity analysis is the method for studying the uncertainty of the output in a system. The output variables of the RC system include the heat flux between the radiant surfaces, the cooling capacity of the system, thermal resistance, and radiant heat transfer coefficient (RHTC). The output variables will be affected by the errors of the uncertain factors, i.e., the emissivity and the absorptivity. Thence, the impact of the surface characters can be described in the way of sensitivity analysis (shown in Eq. (20)). In addition, the reference condition is set to 0.9 separately for emissivity and absorptivity in their single analysis. Thence, it will be easy for us to compare the impact of the factors on the past studies. The method for analyzing the sensitivity is displayed with the following equation:

$$
S_{y, X}=\frac{\frac{\Delta y}{Y}}{\frac{\Delta x}{\bar{X}}} \times 100 \backslash \%
$$

In this study, the sensitivity will be displayed with the change rate of uncertain factors, because it is more intuitively and practicable for showing the difference. The observing range of uncertainty is from 0 to 60 $\%$, which is corresponded to the change range of the emissivity or absorptivity that from 0.9 to 0.4 , based on the previous review of the characters of real building materials. Thence, we could study the impact of the surfaces characters easily.

\subsection{Coefficient of performance for thermal radiation}

Coefficient of performance (COP) shows the cooling effects of air conditioning systems for energy utilization. Thermal radiation is a different method from convention for heat exchange of an air conditioning system. This is the characteristic making the conventional cooling system different from the $\mathrm{RC}$ systems. This character will lead to different impact on the performance of cooling systems. Thence, the heat transfer analysis by the conventional method has to be different from the new model that considering the independence of emissivity and absorptivity. Because, the characters of thermal radiation have been seriously changed. This article use $\eta_{C O P}$ to illustrate the improvement rate of COP for thermal radiation. The improvement rate of COP is compared with the conventional method and it is shown in Eq. (21) (Peng et al. 2019).

$$
\eta_{C O P}=\frac{Q_{o b s}-Q_{c t l}}{Q_{c t l}} \times 100 \backslash \%
$$




\subsection{Exergy method for the improvement of thermal radiation}

Low exergy heating / cooling system is recommended as a sustainable system to utilize the energy with low value (Babiak et al. 2013). Radiant heating / cooling system is a typical low exergy system to use the energy with low temperature. The exergy will be lost during the process of the radiant heat transfer and this part of energy will be converted to other forms of energy. Thence, it is essential to analyze the exergy change for thermal radiation based on the new model in order to investigate the impact of the independence of emissivity and absorptivity. The exergy for a constant cooling surface is given by $\mathrm{Li}$ (Li et al. 2020) and it can be seen as the following. Then, the improvement of exergy could refer to Eq. (21) as well.$$
E X_{Q_{r}}=Q_{r}\left(1-\frac{T_{p}}{T_{1}}\right)
$$ \\ 2.6. Entransy method for the improvement of thermal radiation}

Entransy was put forward by Guo to show the ability of heat transfer (Guo et al. 2007). And, the entransy dissipation means the loss of the ability of heat transfer during a thermal process. Because the independence of emissivity and absorptivity makes it different in the process of thermal radiation from the conventional method, the entransy dissipation will be then influenced for an RC system when designing the cooling demand or thermal environment. The entransy dissipation of radiative heat transfer has been given by Wu (Wu and Liang 2008), and it could be seen in Eq. (23). Then, the improvement of entransy could also refer to Eq. (21).

$$
E n_{\text {diss }, r}=q_{r}\left(T_{1}-T_{p}\right)
$$

\section{Validation Of The New Model}

The validation of the new model will be shown in terms of cooling capacity with experimental data, and the experimental data is referenced from Niu's study (Niu et al. 2014). In which study, there is an internal heat source selected for the validation analysis. Because it is a typical condition to apply an RC system with an internal heat source together. In addition, the original model of heat flux in Niu's study is shown below for comparison with the new model in Eq. (12).

$$
\varphi_{r, p, i}=\frac{\sigma\left(T_{i}^{4}-T_{p}^{4}\right)}{1-\frac{\epsilon_{i}}{\epsilon_{i}} A_{i}+\frac{1}{X_{i, p}} A_{i}+1-\frac{\epsilon_{p}}{\epsilon_{p}} A_{p}}
$$


Figure 3 shows the validation of the new model with the experimental data and the previous simulation data in Niu's Study is provided for comparison. This is a conventional condition with an internal heat source and that the emissivity and absorptivity of all surfaces are 0.9 . The cooling capacity of an RC system is selected as the validation target and it is a widely accepted method for the validation of heat transfer in a radiant room. From Fig. 3, the new simulation data are calculated based on the new model and its trend is consistent with that of the experimental data with the change of characteristic temperature difference. Which is defined as the difference between the air temperature and the mean temperature of supply and return temperature. In Fig. 3 , the average error of the new data is $2.28 \mathrm{~W} / \mathrm{m}^{2}$ and the average relative error is $1.88 \%$. The highest value of the error bar is $5.11 \mathrm{~W} / \mathrm{m}^{2}$ when the character temperature difference is $9 \mathrm{~K}$. While the lowest value is $0.45 \mathrm{~W} / \mathrm{m}^{2}$ when the character temperature difference is $5 \mathrm{~K}$. Additionally, the average error of the original simulation data is $2.96 \mathrm{~W} / \mathrm{m}^{2}$, $0.68 \mathrm{~W} / \mathrm{m}^{2}$ higher than the new data. In addition, the correlation of the new and the original data is 0.994 . These results verify that the new model is well validated with the experimental data and is consistent to the conventional model by the current validation method, although the two models are derived from different mechanisms. The differences on the mechanism will then show up in the further analysis of the models. Thereafter, the sensitivity of the emissivity and absorptivity is further valuable in analyzing the mechanism of the surface characters for RC.

\section{Sensitivity Results}

\subsection{On radiant heat flux}

The heat flux on the first surface (a normal vertical wall) in the reference case is selected as the typical condition for sensitivity analysis. This analysis reveals a basic relationship between the heat flux and the characters of wall surfaces. The result of the sensitivity of uncertain factors is shown in Fig. 4 . Which includes the uncertain factors of absorptivity and emissivity in the developed model. Additionally, the emissivity that is based on the precondition of Kirchhoff's law is concerned at the meantime for telling the mechanism differences between the new model and the traditional theory. Then, the continuity of each analysis is also given to show a quantitative relation in the figures.

In Fig. 4, the sensitivities for the emissivity and absorptivity show the independent impact on the radiant heat flux. Based on the new model, the sensitivity for the emissivity is positive together with that based on Kirchhoff's law. However, it is negative for the absorptivity in the developed model. Furthermore, the sensitivities of the heat flux between two surfaces remains $100 \%$ with the different change rates of emissivity while they are about $21.7 \%$ higher than the average sensitivity of that based on Kirchhoff's law. Moreover, the sensitivity of the absorptivity ranges from $-40 \%$ to $-55 \%$. Such influence is not reflected accordingly under Kirchhoff's law. Hence, this indicates that Kirchhoff's law mainly reflects the influence of the emissivity more than that of the absorptivity. The impact of the absorptivity is almost ignored in the conventional models. 
In order to study the impact on the error estimation, the relative deviation of the heat flux is shown in Fig. 5 . The relative deviation by absorptivity can reach up to $20 \%$ when the absorptivity changes from $5-$ $55 \%$. Which is totally within the error range that was discussed in the previous review. Additionally, the relative deviation for the change of emissivity and that based on Kirchhoff's law that could range around $-60 \%$ when the emissivity is 0.4 . Further, the relative deviation will be $-20 \%$ when the change rate of emissivity is about $20 \%$, which is corresponding to the emissivity of about 0.7 . In other words, the radiant deviation of heat flux will reach about $20 \%$ easily due to the errors of absorptivity and emissivity.

\subsection{On cooling capacity}

The analysis of cooling capacity is shown in Fig. 6 in order to investigate the influence of the independence of emissivity and absorptivity compared with that based on Kirchhoff's law in real engineering. Because the cooling capacity in real thermal environment concerns internal heat sources (e.g., human heat sources or equipment heat sources) and convective heat exchange on walls. Eq. (14)(16) can illustrate the quantitative relationships that resulted in Fig. 6. Moreover, the baseline condition of the results is the same as that for the experimental validation. Thus, we can compare the results intuitively with the real condition.

In Fig. 6, the sensitivity of emissivity is half more affected due to the influence of heat sources and convective heat exchange, compared to the results in Fig. 4. Based on the new model, the sensitivity decreases from $100 \%$ (in Fig. 4) to $44.5 \%$. And, the average sensitivity based on Kirchhoff's law decreases down to $29.8 \%$ from $78.3 \%$, by $61.9 \%$. However, the sensitivity of absorptivity is affected slightly and the average value ranges from $-31.6 \%$ to $-21.7 \%$.

In addition, the relative deviation of the cooling capacity is displayed in Fig. 7. The similar conclusion with the previous analysis of sensitivity could be obtained. The relative deviation with the emissivity in the new model decreases from $-30.6-13.6 \%$, by $55.5 \%$. And, that based on Kirchhoff's law decreases by $61.5 \%$, which is from $-24.6 \%-9.5 \%$. Additionally, the relative deviation of cooling capacity with the absorptivity only decreases by $30.2 \%$. The highest relative deviation is $13.9 \%$ when the absorptivity is 0.4 in Fig. 7, the highest value of the counterpart in Fig. 5 is $19.0 \%$.

\subsection{On radiant heat transfer coefficient}

Spectacularly, the RHTC is an important parameter usually applied in the engineering of RC systems. Thus, the impact on the radiant heat transfer is studied and shown in Fig. 8 and Fig. 9. And, Eq. (18) is the equation to calculate the radiant heat transfer in this study. The baseline value of the radiant heat coefficient in this case is $4.87 \mathrm{~W} /\left(\mathrm{m}^{2} \mathrm{~K}\right)$. Which is in the same range of the results in the past studies.

The sensitivity of the emissivity to the radiant heat transfer remains the same as that to the radiant heat flux, $100 \%$. While the average sensitivity of emissivity based on Kirchhoff's law is slightly smaller than that based on the new model. It is $68.4 \%$ in the normal range of interest in Fig. 8 , and is $9.9 \%$ smaller that of the previous models. This result is a little beyond that from the analysis of the radiant heat flux. It 
implies that models based on Kirchhoff's law will be less sensitive on the heat transfer coefficient further in mechanism about $10 \%$. Moreover, the sensitivity of the absorptivity is increased to $-46.3 \%$. It ranges by $46.6 \%$ from the counterpart value of $-31.6 \%$, in Fig. 4. For analyzing the coefficient of radiant heat transfer, the absorptivity becomes more sensitive. And, the coupling effect of absorptivity could be the reason for the lower sensitivity that based on Kirchhoff's law.

The relative deviation of the coefficient of radiant heat transfer is the key parameter showing the probable error in real, since the coefficient is more preferable in comparison among different engineering cases. The main range of the estimated error is displayed in Fig. 9. This range is concluded from the past experimental studies (also reviewed in Sect. 1).

The relative deviation of the RHTC for the absorptivity in the new model grows from $2.3-29.3 \%$ with the absorptivity decreasing from 0.85 to 0.4 . Its average value rises by $48.9 \%$ compared with the counterpart value of radiant heat flux, which is only $9.9 \%$. Most importantly, the relative deviation with the absorptivity is totally in the range of past experimental studies, when the absorptivity ranges from 0.9 to 0.5 . While the emissivity can only be in the range from 0.9 to 0.75 in the analysis that based on Kirchhoff's law. This implies that the errors caused by the absorptivity is not easy to be perceived in the traditional studies. Because the accuracy range of the emissivity error under Kirchhoff's law is about $70 \%$ smaller than the accuracy range of the absorptivity.

\section{Energy Utilization Based On The New Model}

An investigation on the energy utilization is performed to show the system improvement in heat transfer. The RC system is taken as an example for analyzing the thermal radiation, and two types of terminals are considered, i.e. radiant panels with metal surfaces and capillary mats covered with cement surfaces. Based on the new model, the improvement of the RC system are discussed in terms of COP, exergy and entransy. Additionally, the contamination condition is considered as well to simulate real engineering problems that the absorptivity of indoor surfaces would be affected by contamination, such as by falling dust or oxidation on surfaces. The emissivity and absorptivity for the real surfaces that before and after contamination are listed in Table 1. Further analysis could be found in the following sections.

Table 1

Emissivity and absorptivity for different surfaces

\begin{tabular}{|lll|}
\hline Surfaces & emissivity & absorptivity \\
\hline Metal surface before contamination & 0.95 & 0.9 \\
\hline Metal surface after contamination & 0.9 & 0.85 \\
\hline Cement surface before contamination & 0.85 & 0.7 \\
\hline Cement surface after contamination & 0.8 & 0.75 \\
\hline
\end{tabular}

\subsection{Improvement of COP for thermal radiation}


The improvement rate of COP was shown in Fig. 10 for metal radiant panels, and that shown in Fig. 11 is for conventional RC terminals with cement surfaces. For metal surfaces, based on the new model, the improvement rate of COP is higher than $10 \%$ when the surface is not contaminated. And, it increases slightly from $10.3 \%$ to $11.5 \%$ with the character temperature difference. While the improvement rate for the contaminated surfaces remains around $5 \%$ and shows little change with the character temperature. The results indicates that the COP for metal surfaces is enhanced significantly by the new model. Though the surfaces are contaminated, the improvement rate is still valuable.

For cement surfaces, the improvement rate ranges from $3.3 \%$ to $4.7 \%$, which range is much smaller than that for metal surfaces. However, the improvement rate of COP for contaminated surfaces is negative from $-0.2 \%$ to $-0.8 \%$ with the rise of character temperature difference. This result shows that the improvement of COP for cement surfaces is small, and it could lead to a negative result based on the new model. Hence, it is more meaningful to control the surface characters of emissivity or absorptivity strictly in order to enhance the COP, especially for cement surfaces.

\subsection{Exergy analysis of thermal radiation}

As shown in Fig. 12, the improvement of exergy decreases with character temperature difference before contaminated for metal surfaces. This is inverse from that of COP. However, the improvement rate of exergy is from 14.2 to $17.5 \%$ which is slightly higher than that of COP by about $5 \%$. In addition, the rate for that after contamination is only about $1.6-1.9 \%$ which is much smaller than that before contamination. Except, the performance of exergy is much more sensitive than that of COP. The average decrease of the rate is about $10.5 \%$ when the metal surface is contaminated. This shows the potential of the work by metal RC panels will be heavily affected during the application.

Figure 13 shows the improvement of exergy for RC with cement surfaces. The improvement rate is much lower than that of metal surfaces. The average improvement of exergy is $3.42 \%$ and rises only $0.5 \%$ with the character temperature difference rising from $5 \mathrm{~K}$ to $10 \mathrm{~K}$. Additionally, the exergy improvement decreases with the temperature difference after contamination from $0.55 \%$ to $-0.06 \%$. The improvement of the potential of thermal work for cement surfaces is more limited than that for metal surfaces.

\subsection{Entransy dissipation of thermal radiation}

The results of entransy dissipation for metal and cement surfaces are separately shown in Fig. 14 and Fig. 15. The entransy dissipation of heat transfer for metal surfaces is averagely $15.9 \%$ higher by the new model than that by Kirchhoff's law. It will decrease from $17.9 \%$ to $14.4 \%$ with the rising difference of the character temperature. When the metal surfaces are contaminated, the entransy dissipation will be greatly impacted to an average of $1.7 \%$. This illustrates that the ability of heat transfer for metal surfaces is increasingly enhanced. It may be the main reason for the rising improvement rate of COP for thermal radiation, though the exergy is also enhanced. However, the enhanced exergy only means more potential for thermal work not the ability of heat transfer. 
In addition, the results for cement surfaces are also limited in entransy dissipation. The average dissipation is about $3.46 \%$ before contaminated and it is only $0.28 \%$ for that contaminated. The results show that the ability of heat transfer is remarkably enhanced by the new model. Additionally, the new model can also be applied for a more detailed analysis by the independence of emissivity and absorptivity.

\section{Discussion}

\subsection{The inapplicability of Kirchhoff's law for indoor thermal radiation}

Kirchhoff's law states that a body in thermodynamic equilibrium releases as much energy as it absorbs in each direction and at each wavelength (Lienhard IV et al. 2018). For a surface, if the energy absorbed is not equal to that the surface releases, the thermodynamic equilibrium is invalid. The radiative heat will be absorbed in a very thin depth that the heat penetrates through the surface, as shown in Fig. 16. This penetration depth indeed exist for thermal radiation between two plates in practice (Basu and Zhang 2009). For metals, the penetration depth is about $1 \mu \mathrm{m}$ and the depth for the material of indoor surfaces will not be deeper than $1 \mathrm{~mm}$ (Yang and Tao 2006). Together with this depth, the wall surface forms a radiant surface layer with a volume as shown in Fig. 16. And, the thermophysical properties of the surface layer, e.g., thermal capacity and conduction, are assigned by the material inside this volume. For most building materials, e.g., concrete and cement, the specific heat are relatively high. The high specific heat will then lead to the high heat storage for the surface layer and then make the thermal equilibrium invalid in the local layer, due to that the energy absorbed on the surface $\left(E_{s t r}+E_{c o n}\right.$ in Fig. 16) is not equal to that released $\left(E_{c o n}\right)$. The rest part of energy $\left(E_{s t r}\right)$ is stored by the surface itself for enhancing the surface temperature.

It is neither likely for real materials to be simplified into the conditions that they are applicable for Kirchhoff's law on radiant surfaces in indoor. There is little research on the precondition of applying Kirchhoff's law. Thus, we can define an indice $\eta$ to show the ratio of energy stored to that released for the surface layer in a unit time, shown as the following, in order to decide whether Kirchhoff's law is appropriate to be applied.

\begin{tabular}{|l|}
\hline$\eta=\frac{E_{\text {str }}}{E_{\text {con }}}$ \\
\hline Where, \\
\hline$E_{\text {str }}=\frac{1}{2} c m \Delta T$ \\
$E_{\text {con }}=k \frac{\Delta T}{\delta}$
\end{tabular}


If $\eta$ of a real surface is larger than 1 , it indicates that there is more heat stored than that released. In other words, the energy is more easily to be stored than to be transferred. Thus, the local thermodynamic equilibrium is impossible, because the energy absorbed from thermal radiation is not equal to that released from the surface layer. Thence, Kirchhoff's law is inapplicable for this real surface and vice versa.

Three common building materials are taken as examples to discuss the applicability of Kirchhoff's law in reality. And, the thermophysical data are obtained from (Lienhard IV et al. 2018). As the penetration depth is very thin, the character length is assumed as $1 \mathrm{~mm}$ temporally in Eq. (27) to show the influences. The analyzing results of the building materials for the same depth by thermal radiation can be seen in Table 2 companied with their other thermophysical data.

Table 2

Thermophysical properties of common building materials

\begin{tabular}{|llllll|}
\hline Materials & $\begin{array}{l}\text { Density } \\
\left(\mathbf{k g} / \mathrm{m}^{3}\right)\end{array}$ & $\begin{array}{l}\text { Specific heat } \\
(\mathrm{J} / \mathrm{kgK})\end{array}$ & $\begin{array}{l}\text { Thermal conductivity } \\
(\mathrm{W} / \mathrm{mK})\end{array}$ & $\begin{array}{l}\text { Thermal diffusivity } \\
\left(\mathrm{m}^{2} / \mathbf{s}\right)\end{array}$ & $\eta$ \\
\hline Concrete & 1850 & 900 & 0.1 & $6.00601 \mathrm{E}-08$ & 8.33 \\
\hline $\begin{array}{l}\text { Brick } \\
\text { (common) }\end{array}$ & 2000 & 720 & 0.7 & $4.86111 \mathrm{E}-07$ & 1.03 \\
\hline Aluminum & 2707 & 905 & 9.61 & $3.92271 \mathrm{E}-06$ & 0.13 \\
\hline
\end{tabular}

From Table 2, the $\eta$ of concrete and common brick are both larger than 1. Only the $\eta$ of aluminum is 0.13 . In addition, we can find the thermal conductivities of concrete and brick are much smaller than aluminum. This indicates that real materials with good thermal conductivity are easily to obtain the $\eta$ which is smaller than 1 . Hence, only such materials are possible to apply Kirchhoff's law by simplifying the local surface as thermodynamic equilibrium. However, for most building materials, the application of Kirchhoff's law is unreasonable due to the low thermal conductivity.

\subsection{The bias existing in the past experimental validation}

Then results of sensitivity in Sect. 4 show that the sensitivity of the target valuables (i.e., radiant heat flux, cooling capacity, and radiant heat transfer coefficient) to the absorptivity is inversely proportional to the emissivity. Although the sensitivity of the emissivity is nearly twice that of the absorptivity, the relative deviation of radiant heat flux will reach about $20 \%$ when the absorptivity changes $55 \%$. The change rate of the absorptivity is totally in the normal error range according to the previous tests (reviewed in Sect. 1). Hence, if the error of the absorptivity reaches $55 \%$, the error of the radiant heat flux in reality will be $20 \%$. Additionally, this error will be ignored as long as the thermal model for analysis is based on Kirchhoff's law.

Furthermore, the results of sensitivity and deviation based on Kirchhoff's law are highly correlated to the results of the independent emissivity in the new model by comparison. This implies that Kirchhoff's law 
can reflect more of the impact of emission, other than that of absorption. Besides, the accuracy range due to the emissivity error in the analysis based on Kirchhoff's law is about 70\% lower than that by the absorptivity. Therefore, the real reasons for the heat exchange in RC systems could not be given accurately by the analyzing method based on Kirchhoff's law. Hence, this error and its further impact in engineering has to be neglected.

However, the results of the past models based on Kirchhoff's law possibly exists a wide survivor's bias. For example, in this study, the coefficient of radiant heat transfer is $4.87 \mathrm{~W} /\left(\mathrm{m}^{2} \mathrm{~K}\right)$. Based on Fig. 9 , if the absorptivity changes $28 \%$ to 0.65 , the coefficient will be $5.5 \mathrm{~W} /\left(\mathrm{m}^{2} \mathrm{~K}\right)$ which is just the recommended coefficient that given based on past engineering practice. This shows if the absorptivity error of $28 \%$ is neglected in a real experiment, a considerable error for RHTC that obtained by Kirchhoff's law will be generated, but it will not arise any attention by the results of the past experimental studies. However, this will lead to the error of about $20 \%$ in radiant heat flux, as shown in Fig. 5 . Furthermore, there is not enough solid evidence that can explain the differences of the errors in the past experimental validation that based on Kirchhoff's law. Therefore, the validation of the past experimental studies are highly coincidental in radiant heat flux without verifying the real value of absorptivity.

Except, the past method for the validation of the radiant heat flux was indeed self-verification, though based on the experimental data (which includes the heat flux of convection as well). For instance, the past method can only test the total cooling capacity, not the radiant heat flux or the convective heat flux (Shinoda et al. 2019). The radiant heat flux or convective heat flux is obtained by abstracting the other part from the total when the convective part or radiant part is calculated. Hence, such validation of radiant heat flux is unreasonable unless it is compared with the experimental data of radiant heat flux. Thence, a direct test of radiant heat flux for testing its coefficient will be the final way to solve the problem in future.

\section{Conclusion}

This study is aiming to investigate the reliability of the current models for analyzing the radiant heat transfer. One developed model is put forward for studying the error mechanism during the process of radiant heat transfer. The new model concerns the independence of the surface emissivity and absorptivity. Additionally, the new model has been validated by the experimental data in the study. Finally, the new model is found more reasonable and adaptable closing to real conditions than the conventional methods that based on Kirchhoff's law. Main results could be summarized as the follows:

1. The computational reliability of the thermal analysis under radiant environment is theoretically enhanced by the new model. The independent impact by the absorptivity is concerned. The reason for the error of $20 \%$ can be separately attributed into the two independent factors, according to the developed model. Additionally, the COP of RC systems can be enhanced by $10 \%$ based on the new model. The improvement of entransy could be the reason for the higher COP. 
2. The results of the validation show that the prediction of the new model is consistent with that of the reference study under the same conditions. The average error of the cooling capacity for the new model is $2.28 \mathrm{~W} / \mathrm{m}^{2}, 0.68 \mathrm{~W} / \mathrm{m}^{2}$ smaller than that of the reference data. In addition, the relative error is only $1.88 \%$ compared with the experimental data. Thence, the errors could be regarded small enough as validation for the new model to have a deep study on the mechanism.

3. Based on the new model, this article takes a typical condition for studying the sensitivity and relative deviation of the uncertain factors (i.e., emissivity and absorptivity). The results show that the sensitivities of the heat flux, cooling capacity, and heat transfer coefficient are positive to the emissivity, but are negative to the absorptivity. The sensitivities of the above variables are separately around $-45 \%,-25 \%$ and $-45 \%$. Nevertheless, based on Kirchhoff's law, the sensitivities of the variables are about $75 \%, 30 \%$, and $75 \%$, the results are nearly $15 \%$ smaller than the sensitivity of emissivity. Hence, the Kirchhoff's law reflects the impact of emissivity much more than that of absorptivity.

4. The validation of radiant heat flux in past studies were highly insufficient. Under the same condition, radiant heat flux can be impacted to increase by $20 \%$ when the absorptivity decreases from 0.9 to 0.4 . This error range should not be accepted in the analysis of engineering, but this range happens to be under the observation of past studies. Besides, the RHTC in this study is $4.87 \mathrm{~W} /\left(\mathrm{m}^{2} \mathrm{~K}\right)$. And, it will increase to $5.5 \mathrm{~W} /\left(\mathrm{m}^{2} \mathrm{~K}\right)$ when the absorptivity decreases from 0.9 to 0.65 . The latter coefficient is equal to the recommended value by experience. Hence, the results of current models based on Kirchhoff's law were highly coincidence. In addition, the past models were lack of enough experimental validation for the comparison and deep analysis. Only an independent test of radiant heat flux is the most convincing method to validate the theories. Therefore, the independent test of radiant heat flux is a key development for the future research of radiant heat exchange in indoor.

\section{Abbreviations}




\section{Symbols}

$A \quad$ the area of a surface $\left(\mathrm{m}^{2}\right)$

c the specific heat of the surface layer $(\mathrm{kJ} / \mathrm{kg})$

$E \quad$ the emission energy by a surface itself (W)

$E_{c o n}$ the energy released by the surface layer in a unit time $(\mathrm{J} / \mathrm{s})$

$E n \quad$ the entransy for a thermal process (JK) $\quad \eta$

$E_{s t r}$ the energy stored in the surface layer in $\theta$ a unit time $(\mathrm{J} / \mathrm{s})$

Ex the exergy for a thermal process $(\mathrm{J})$

$G \quad$ the locally incident radiation heat flux (W)

$h \quad$ the heat transfer coefficient $\left[\mathrm{W} /\left(\mathrm{m}^{2} \mathrm{~K}\right)\right] \quad \Phi_{1,2}$

$J \quad$ the total radiosity leaving by combined emission and reflection (W)

$k \quad$ the thermal conductivity of the thermal layer $(\mathrm{W} / \mathrm{mK})$

$m \quad$ the mass of the surface layer $(\mathrm{kg})$

1 any surface 1

$Q \quad$ the amount of heat flux (W)

2 any surface 2

$q$ the density of heat flux $\left(\mathrm{W} / \mathrm{m}^{2}\right)$

1-5 from the specific surface 1 to 5

$R \quad$ the reflection energy of

a air

$S \quad$ the length for radiation between two surfaces $(m)$

$S_{y, x} \quad$ the sensitivity of $\mathrm{x}$ to $\mathrm{y}(\%)$

c convective heat exchange

$T$ the temperature of a radiant surface (K)

$x \quad$ the uncertain factor in a sensitivity analysis

$x_{1,2}$ the view factor from surface 1 to 2

$y \quad$ the target variable of a sensitivity analysis

\section{Subscripts}

b blackbody

ctl control group

diss dissipation

i internal heat source

obs observation group
$\Delta T \quad$ the temperature difference of the surface layer from the surface to the inner $(\mathrm{K})$

$\Delta x \quad$ the variation of the uncertain factor

$\Delta y \quad$ the variation of the target variable the emissivity of a surface an efficiency or improvement rate (\%) the normal angle of thermal radiation on a surface $\left(^{\circ}\right)$

the quantity of radiar
surface 1 to 2 (W) 


$\begin{array}{llll}a & \text { the absorptivity for a surface } & p & \text { cooling panel } \\ \delta & \text { the penetration depth for thermal } & r & \text { radiant heat exchange }\end{array}$
radiation $(\mathrm{m})$

\section{Declarations}

\section{Ethics approval and consent to participate}

Disclosure of potential conflicts of interest

Research involving Human Participants and/or Animals

Informed consent.

\section{Consent for publication}

Not applicable.

\section{Availability of data and materials}

The datasets used and/or analyzed during the current study are available from the corresponding author on reasonable request.

\section{Competing interests}

The authors did not receive support from any organization for the submitted work.

\section{Funding}

Not applicable.

\section{Authors Contributions}

All authors contributed to the study conception and design. Material preparation, data collection and analysis were performed by Fan Zhang and Guoqiang Zhang. The first draft of the manuscript was written by Fan Zhang and all authors commented on previous versions of the manuscript. All authors read and approved the final manuscript. 


\section{Acknowledgement}

Not applicable.

\section{References}

1. Acikgoz O, Kincay O (2015) Experimental and numerical investigation of the correlation between radiative and convective heat-transfer coefficients at the cooled wall of a real-sized room. Energy Build 108:257-266. https://doi.org/10.1016/j.enbuild.2015.09.013

2. ASHRAE (2016) 2016 ASHRAE Handbook - HVAC Systems and Equipment. American Society of Heating, Refrigerating, and Air Conditioning Engineers, Atlanta, GA

3. Babiak J, Olesen BW, Petráš D (2013) Low Temperature Heating and High Temperature Cooling Embedded Water Based Surface Heating and Cooling Systems, 3rd edn. REHVA

4. Basu S, Zhang ZM (2009) Ultrasmall penetration depth in nanoscale thermal radiation. Appl Phys Lett 95:. https://doi.org/10.1063/1.3238315

5. Bueno B, Norford L, Pigeon G, Britter R (2012) A resistance-capacitance network model for the analysis of the interactions between the energy performance of buildings and the urban climate. Build Environ 54:116-125. https://doi.org/10.1016/j.buildenv.2012.01.023

6. Carnielo E, Zinzi M, Fanchiotti A (2014) On the Solar Reflectance Angular Dependence of Opaque Construction Materials and Impact on the Energy Balance of Building Components. Energy Procedia 48:1244-1253. https://doi.org/10.1016/j.egypro.2014.02.141

7. Causone F, Corgnati SP, Filippi M, Olesen BW (2009) Experimental evaluation of heat transfer coefficients between radiant ceiling and room. Energy Build 41:622-628. https://doi.org/10.1016/j.enbuild.2009.01.004

8. Cholewa T, Anasiewicz R, Siuta-Olcha A, Skwarczynski MA (2017) On the heat transfer coefficients between heated/cooled radiant ceiling and room. Appl Therm Eng 117:76-84. https://doi.org/10.1016/j.applthermaleng.2017.02.019

9. Feng J, Schiavon S, Bauman F (2016) New method for the design of radiant floor cooling systems with solar radiation. Energy Build 125:9-18. https://doi.org/10.1016/j.enbuild.2016.04.048

10. Guo ZY, Zhu HY, Liang XG (2007) Entransy-A physical quantity describing heat transfer ability. Int J Heat Mass Transf 50:2545-2556. https://doi.org/10.1016/j.ijheatmasstransfer.2006.11.034

11. Howell JR, Menguc MP, Siegel R (2015) Thermal Radiation Heat Transfer. CRC Press

12. Karadağ $R$ (2009) The investigation of relation between radiative and convective heat transfer coefficients at the ceiling in a cooled ceiling room. Energy Convers Manag 50:1-5. https://doi.org/10.1016/j.enconman.2008.09.008

13. Koca A, Çetin G (2017) Experimental investigation on the heat transfer coefficients of radiant heating systems: Wall, ceiling and wall-ceiling integration. Energy Build 148:311-326. https://doi.org/10.1016/j.enbuild.2017.05.027 
14. Koca A, Gemici Z, Topacoglu Y, et al (2014) Experimental investigation of heat transfer coefficients between hydronic radiant heated wall and room. Energy Build 82:211-221. https://doi.org/10.1016/j.enbuild.2014.06.045

15. Li Z, Zhang D, Chen X, Li C (2020) A comparative study on energy saving and economic efficiency of different cooling terminals based on exergy analysis. J Build Eng 30:101224. https://doi.org/10.1016/j.jobe.2020.101224

16. Lienhard IV JH, Lienhard V JH, Liehman (2018) A Heat Transfer Textbook, 4th edn. Phlogiston Press, Cambridge, MA

17. Liu W, Geng Y (2004) Experimental study on solar radiation absorption rate of concrete surface. China Concr Cem Prod 8:8-11. https://doi.org/10.19761/j.1000-4637.2004.04.003

18. Modest MF (2013) Radiative Heat Transfer, third edit. Elsevier, Oxford

19. Niu X, Tian Z, Duan B, Wang Z (2014) Influences of heat source forms on the cooling capacity of the radiant cooling terminal. Energy Build 102-111. https://doi.org/10.1016/j.enbuild.2013.12.013

20. Olesen BW, Michel E, Bonnefoi F, De Carli M (2000) Heat exchange coefficient between floor surface and space by floor cooling - theory or a question of definition. In: ASHRAE Transactions

21. Peng $P$, Gong G, Mei $X$, et al (2019) Investigation on thermal comfort of air carrying energy radiant airconditioning system in south-central China. Energy Build 182:51-60.

https://doi.org/10.1016/j.enbuild.2018.10.020

22. Rhee KN, Olesen BW, Kim KW (2017) Ten questions about radiant heating and cooling systems. Build Environ 112:367-381. https://doi.org/10.1016/j.buildenv.2016.11.030

23. Saber EM, Tham KW, Leibundgut $H$ (2016) A review of high temperature cooling systems in tropical buildings. Build Environ 96:237-249. https://doi.org/10.1016/j.buildenv.2015.11.029

24. Shinoda J, Kazanci OB, Tanabe S, Olesen BW (2019) A review of the surface heat transfer coefficients of radiant heating and cooling systems. Build Environ 159:106156. https://doi.org/10.1016/j.buildenv.2019.05.034

25. Su L, Li N, Zhang X, et al (2015) Heat transfer and cooling characteristics of concrete ceiling radiant cooling panel. Appl Therm Eng 84:170-179. https://doi.org/10.1016/j.applthermaleng.2015.03.045

26. Wang Z, Horseman T, Straub AP, et al (2019) Pathways and challenges for efficient solar-thermal desalination. Sci Adv 5:eaax0763. https://doi.org/10.1126/sciadv.aax0763

27. Weber T, Jóhannesson G (2005) An optimized RC-network for thermally activated building components. Build Environ 40:1-14. https://doi.org/10.1016/j.buildenv.2004.04.012

28. Wu J, Liang XG (2008) Application of entransy dissipation extremum principle in radiative heat transfer optimization. Sci China, Ser E Technol Sci 51:1306-1314. https://doi.org/10.1007/s11431008-0141-6

29. Yang S, Tao W (2006) Heat transfer, 4th editio. Higher Education Press (HEP), Xi'an

30. Zhang D, Xia X, Cai N (2016) A dynamic simplified model of radiant ceiling cooling integrated with underfloor ventilation system. Appl Therm Eng 106:415-422. 
https://doi.org/10.1016/j.applthermaleng.2016.06.017

31. Zhang F, Guo H-A, Liu Z, Zhang G (2021) A critical review of the research about radiant cooling systems in China. Energy Build 235:110756. https://doi.org/10.1016/j.enbuild.2021.110756

32. Zhang HH, Sha WEl, Huang ZX, Shi GM (2018) Flexible and Accurate Simulation of Radiation Cooling with FETD Method. Sci Rep 8:2652. https://doi.org/10.1038/s41598-018-21020-w

33. Zhao K, Liu X-H, Jiang Y (2015) Cooling capacity prediction of radiant floors in large spaces of an airport. Sol Energy 113:221-235. https://doi.org/10.1016/j.solener.2015.01.003

34. Zhou X, Liu Y, Luo M, et al (2019) Thermal comfort under radiant asymmetries of floor cooling system in $2 \mathrm{~h}$ and $8 \mathrm{~h}$ exposure durations. Energy Build 188-189:98-110. https://doi.org/10.1016/j.enbuild.2019.02.009

\section{Figures}

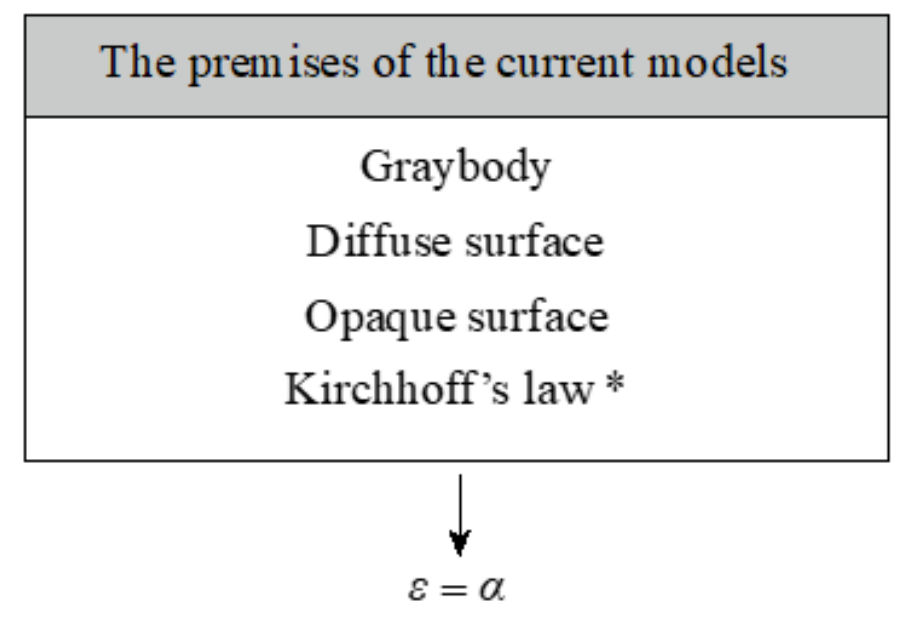

(a)

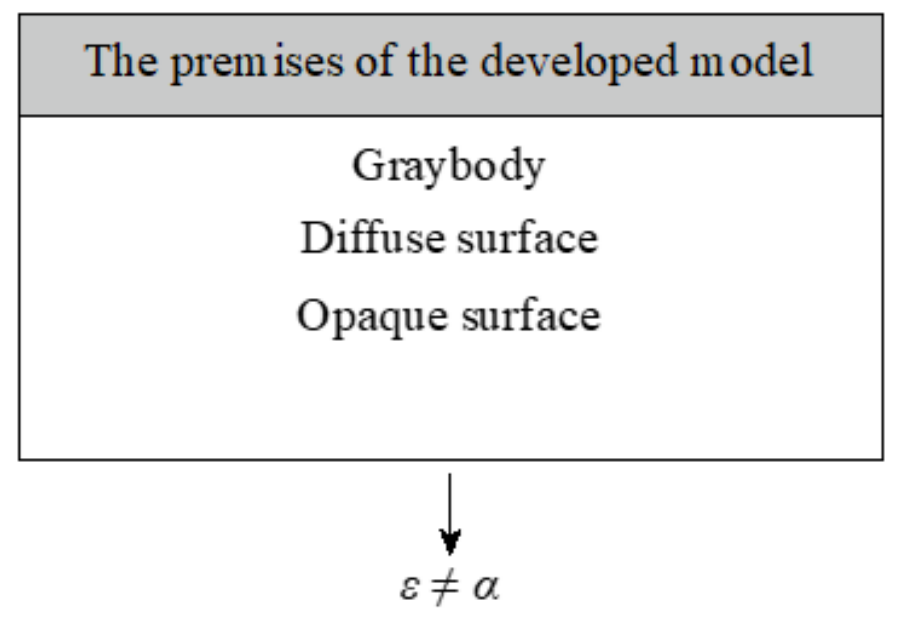

(b)

* Hidden premises for applying Kirchhoff's law:

1. High conductivity for the surface material

2. Local thermal equilibrium

\section{Figure 1}

The comparison between the premises of the current models and the developed model

\section{Figure 2}

Key information and its nodal model for the reference case 


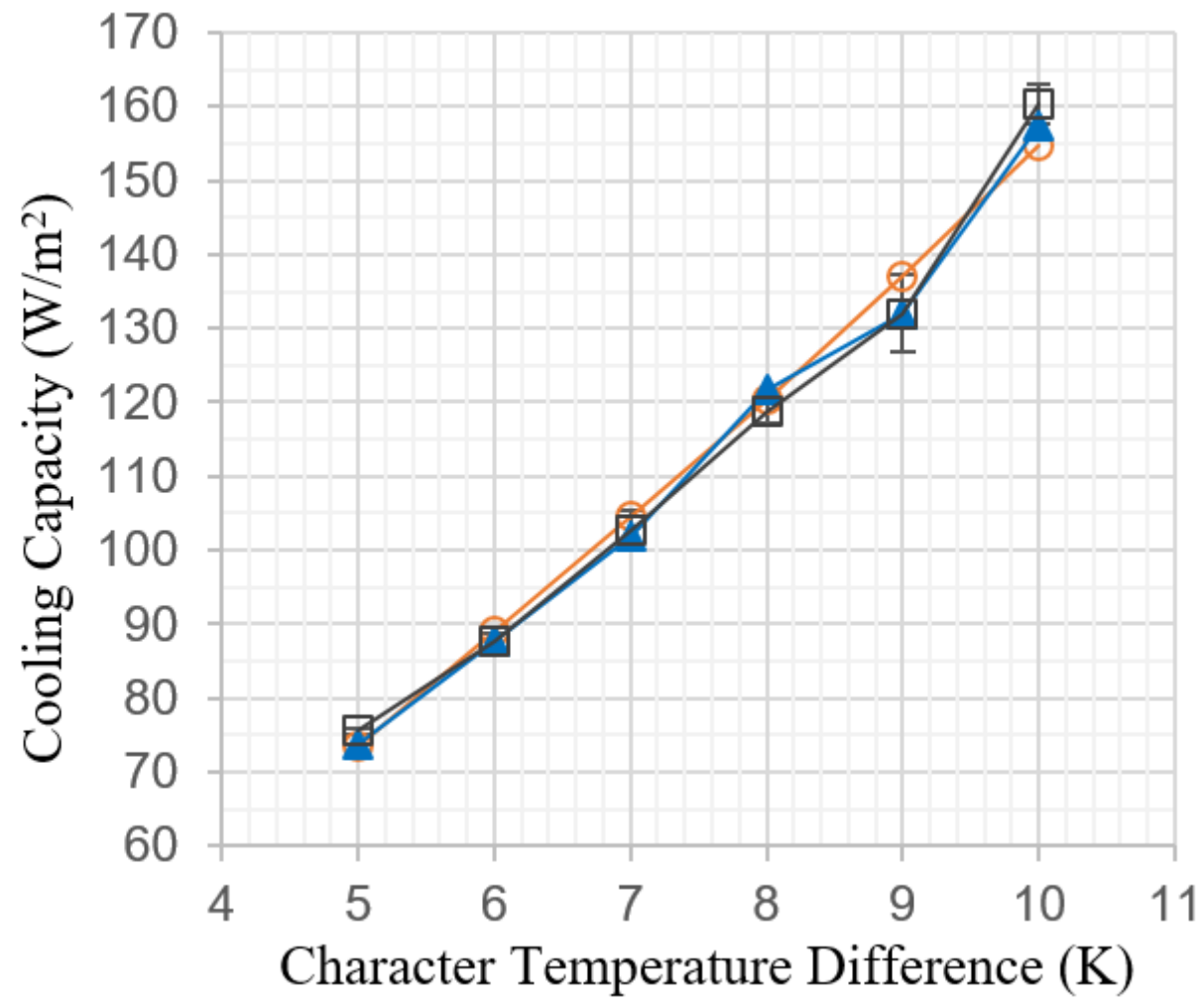

$\frown$ Experimental data

$\neg-$ New Simulation Data

$\square$ Original Simulation Data

\section{Figure 3}

Validation of the new model for an RC room

Value of Uncertain Factor

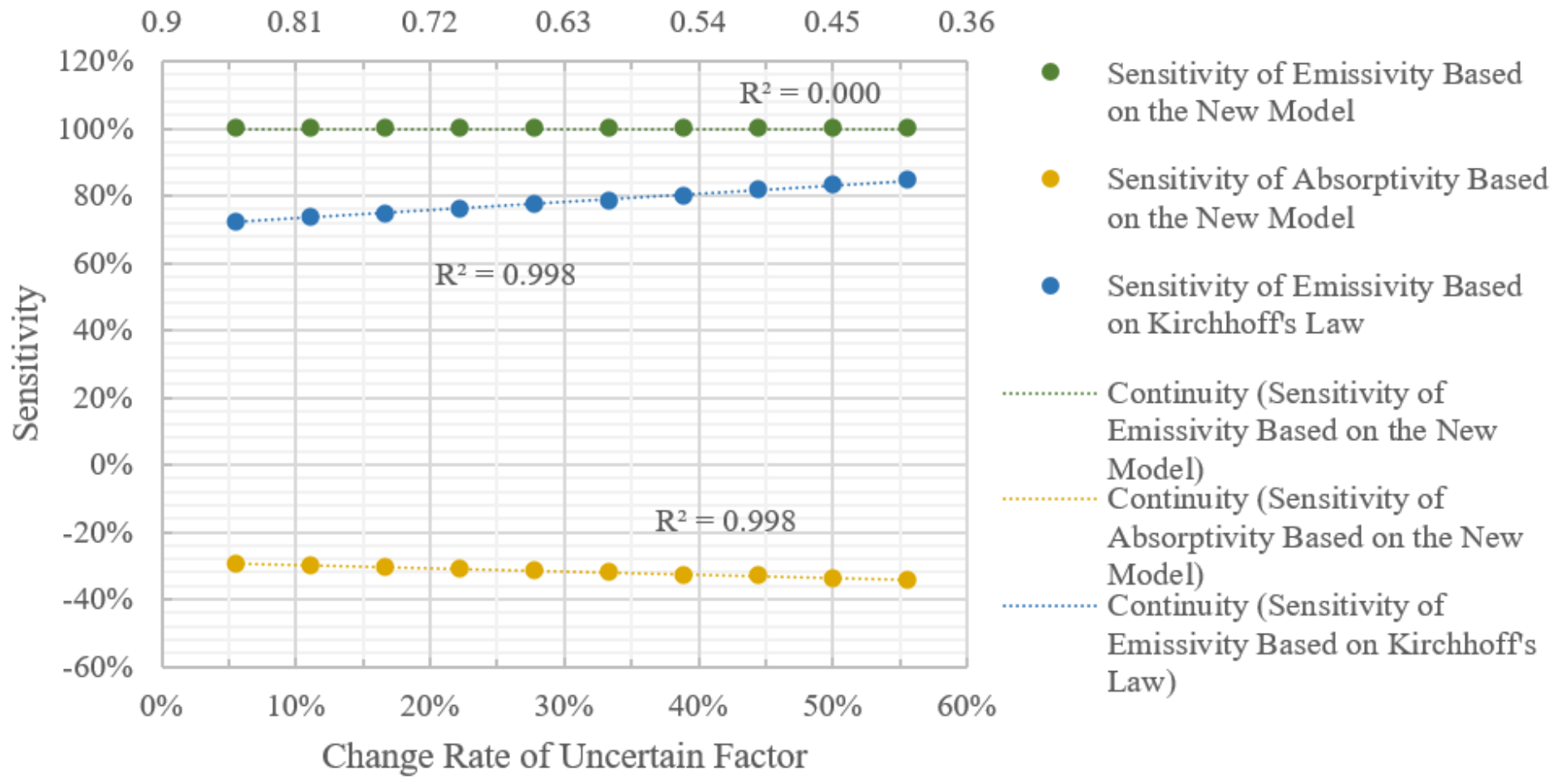

Figure 4 
The sensitivity of uncertain factors between for the heat flux

Value of Uncertain Factor

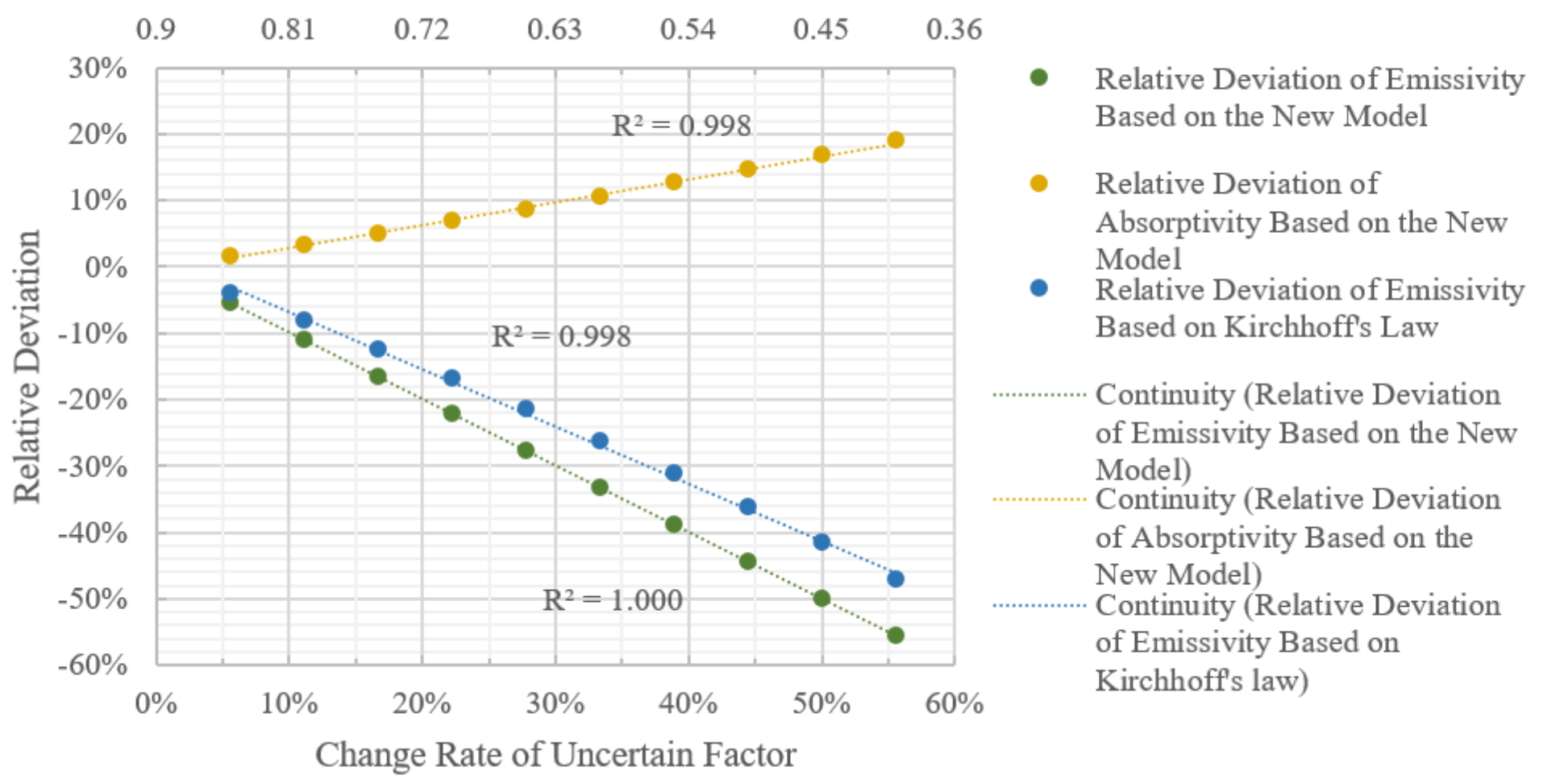

\section{Figure 5}

The relative deviation of the heat flux with the change of uncertain factors Value of Uncertain Factor

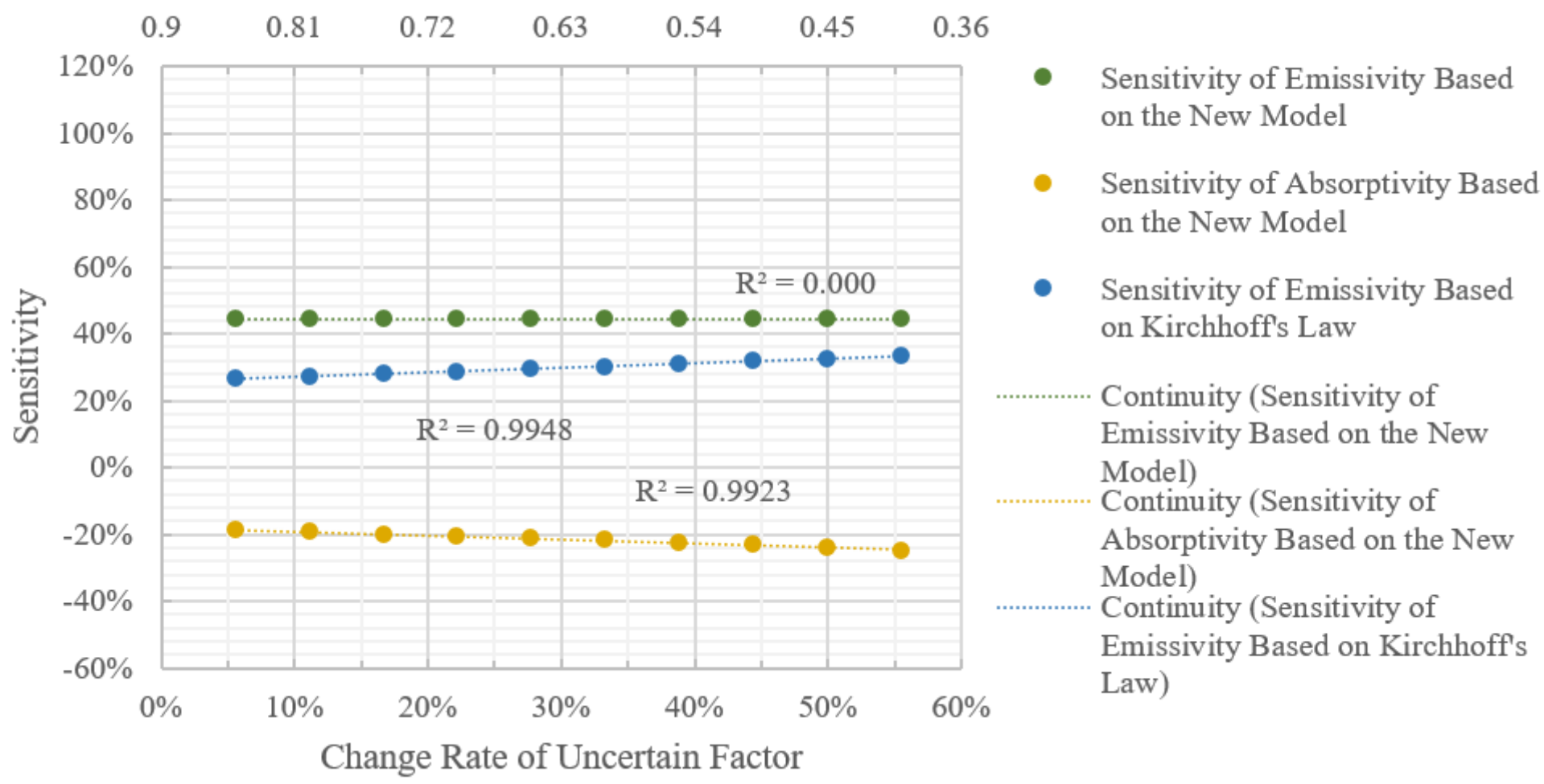

Figure 6 
The sensitivity of the uncertain factors for the cooling capacity

\section{Value of Uncertain Factor}

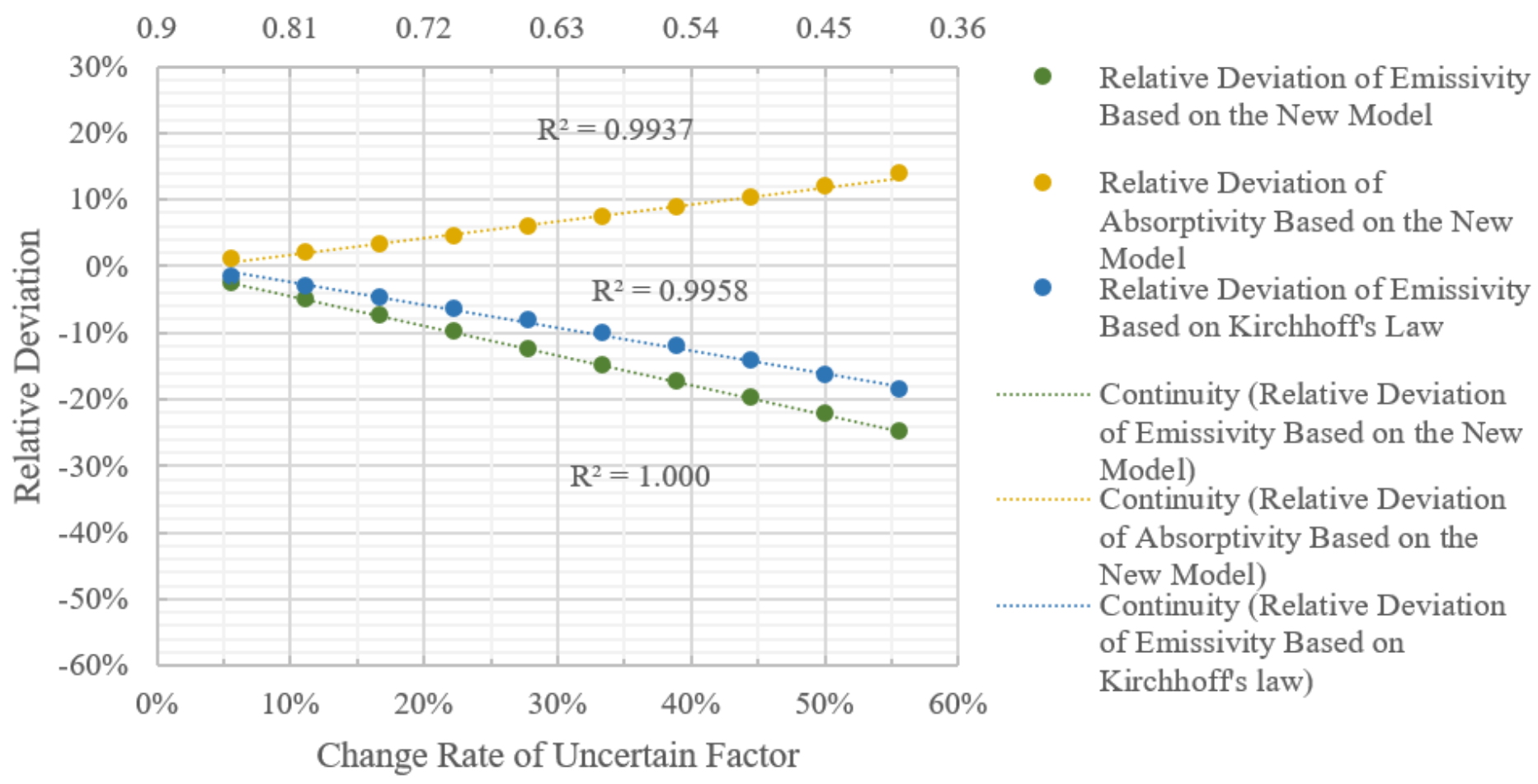

\section{Figure 7}

The relative deviation of the cooling capacity with the change of uncertain factors

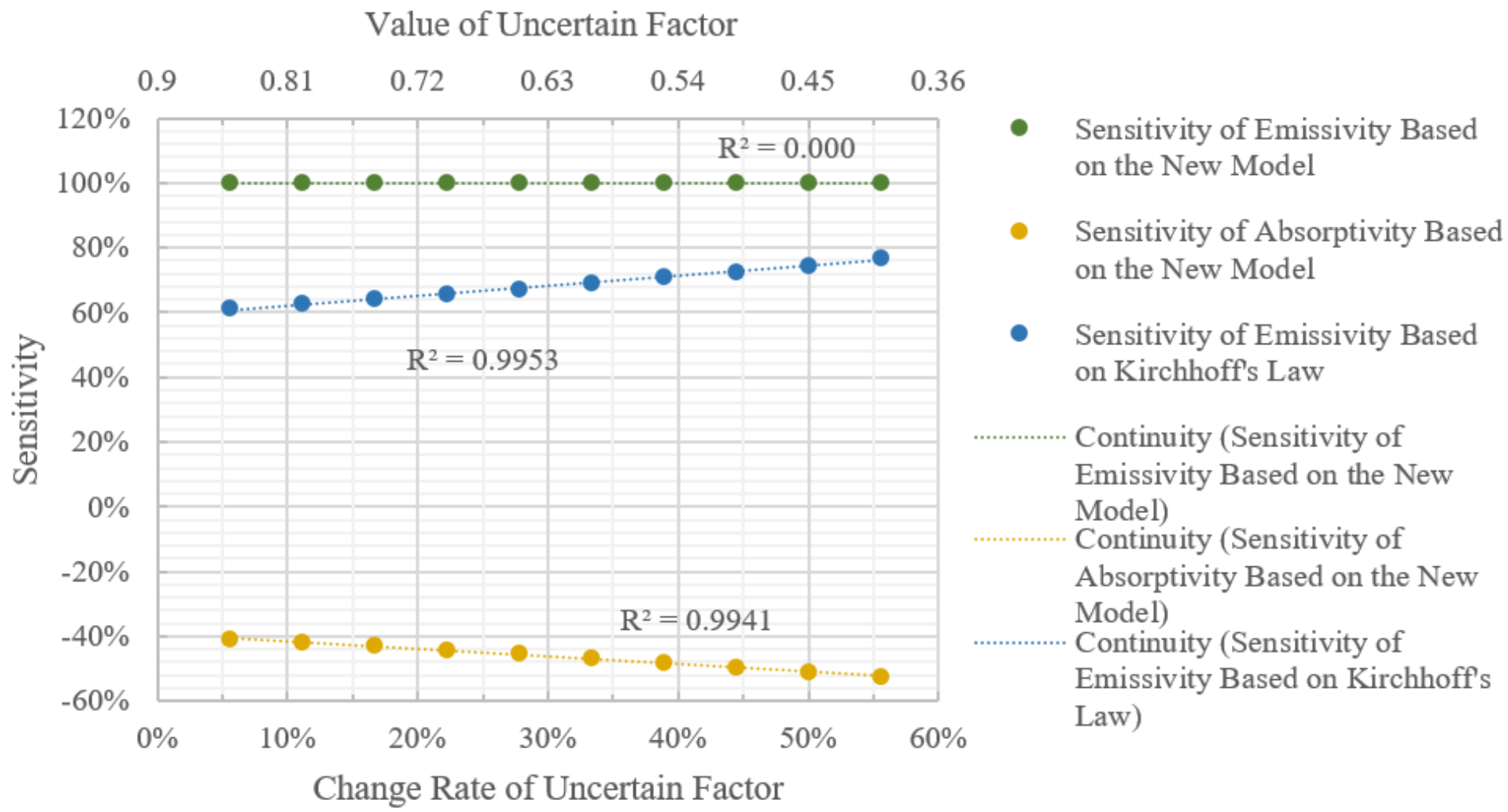

Figure 8 
The sensitivity of the uncertain factors for the heat transfer coefficient

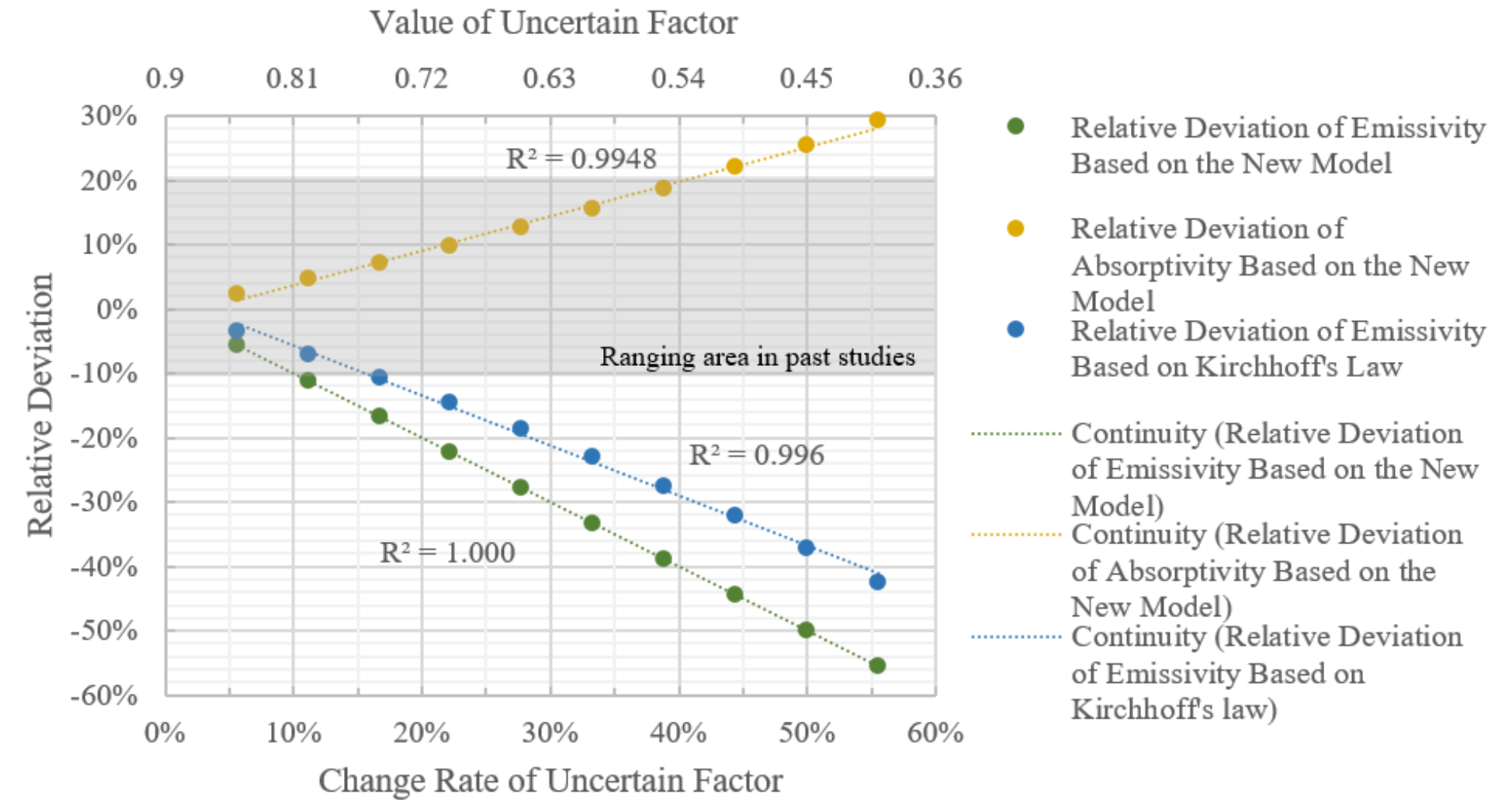

\section{Figure 9}

The relative deviation of the heat transfer coefficient with the change of uncertain factors

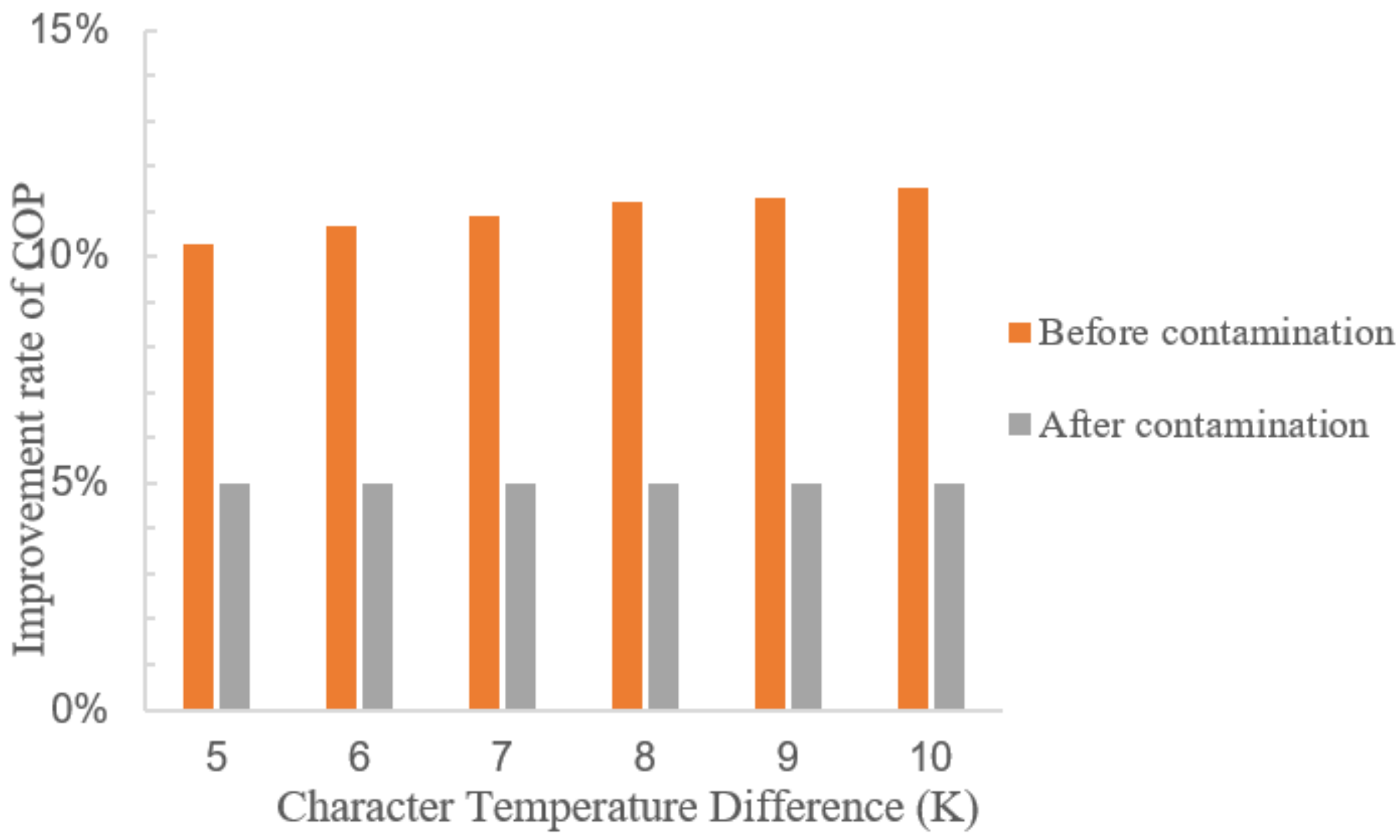


Figure 10

Improvement of COP for metal RC panels

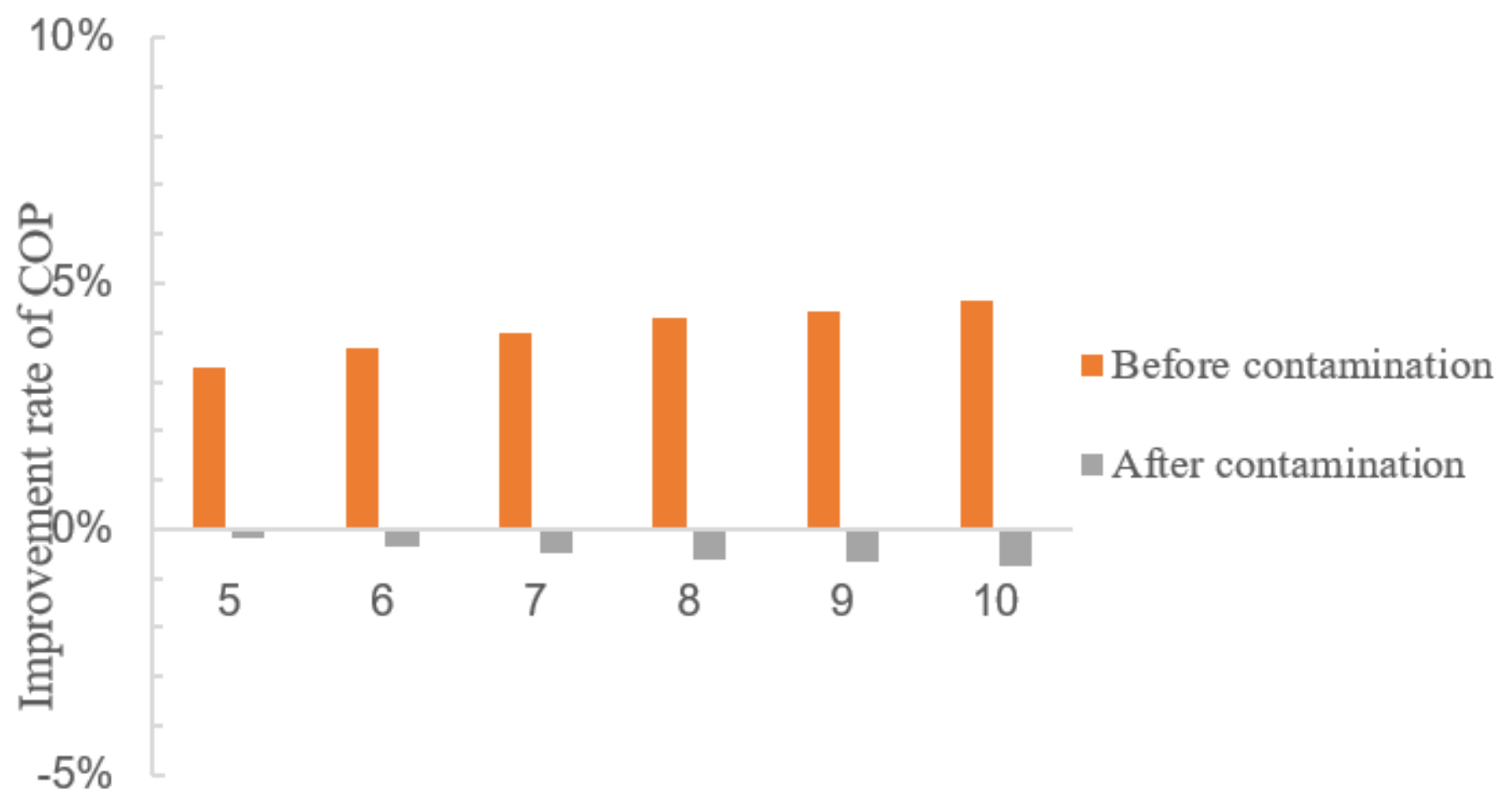

\section{Character Temperature Difference (K)}

Figure 11

Improvement of COP for RC with cement surfaces 


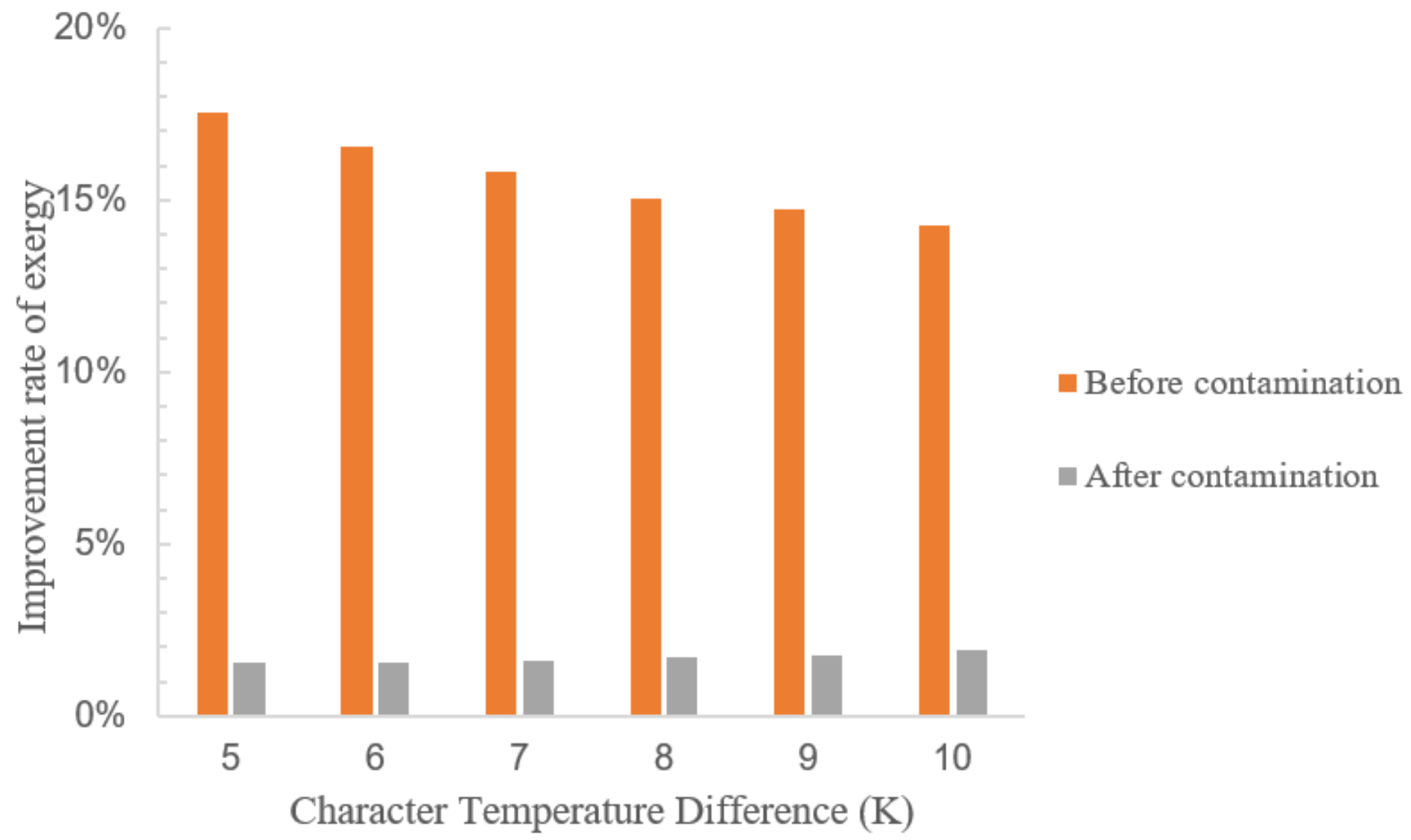

Figure 12

Improvement of exergy for metal RC panels

Figure 13

Improvement of exergy for RC with cement surfaces

Figure 14

Improvement of entransy for metal RC panels

Figure 15

Improvement of entransy for RC with cement surfaces

Figure 16

The penetration depth for thermal radiation on a surface 